\title{
Behavioural and neurophysiological differences in working memory function of depressed patients and healthy controls
}

Citation for published version (APA):

Nikolin, S., Tan, Y. Y., Martin, D., Moffa, A., Loo, C. K., \& Boonstra, T. W. (2021). Behavioural and neurophysiological differences in working memory function of depressed patients and healthy controls. Journal of Affective Disorders, 295, 559-568. https://doi.org/10.1016/j.jad.2021.08.083

Document status and date:

Published: 01/12/2021

DOI:

10.1016/j.jad.2021.08.083

Document Version:

Publisher's PDF, also known as Version of record

Document license:

Taverne

Please check the document version of this publication:

- A submitted manuscript is the version of the article upon submission and before peer-review. There can be important differences between the submitted version and the official published version of record.

People interested in the research are advised to contact the author for the final version of the publication, or visit the DOI to the publisher's website.

- The final author version and the galley proof are versions of the publication after peer review.

- The final published version features the final layout of the paper including the volume, issue and page numbers.

Link to publication

\footnotetext{
General rights rights.

- You may freely distribute the URL identifying the publication in the public portal. please follow below link for the End User Agreement:

www.umlib.nl/taverne-license

Take down policy

If you believe that this document breaches copyright please contact us at:

repository@maastrichtuniversity.nl

providing details and we will investigate your claim.
}

Copyright and moral rights for the publications made accessible in the public portal are retained by the authors and/or other copyright owners and it is a condition of accessing publications that users recognise and abide by the legal requirements associated with these

- Users may download and print one copy of any publication from the public portal for the purpose of private study or research.

- You may not further distribute the material or use it for any profit-making activity or commercial gain

If the publication is distributed under the terms of Article $25 \mathrm{fa}$ of the Dutch Copyright Act, indicated by the "Taverne" license above, 
Research paper

\title{
Behavioural and neurophysiological differences in working memory function of depressed patients and healthy controls
}

\author{
Stevan Nikolin ${ }^{\text {a,b, }}$, Yi Yin Tan ${ }^{\text {a }}$, Donel Martin ${ }^{\text {a,b }}$, Adriano Moffa ${ }^{\text {a }}$, Colleen K. Loo ${ }^{\text {a,b,c }}$, \\ Tjeerd W. Boonstra ${ }^{a, d}$
}

${ }^{a}$ School of Psychiatry, University of New South Wales, Sydney, Australia

${ }^{\mathrm{b}}$ Black Dog Institute, Hospital Road, Sydney, Randwick NSW 2031, Australia

${ }^{\mathrm{c}}$ St. George Hospital, Sydney, Australia

d Faculty of Psychology and Neuroscience, Maastricht University, Maastricht, the Netherlands

\section{A R T I C L E I N F O}

\section{Keywords:}

Depression

Working memory

Electroencephalography

Event-related potentials

Frontal theta

\begin{abstract}
A B S T R A C T
Objective: Major depressive disorder (MDD) is associated with deficits in working memory. Several cognitive subprocesses interact to produce working memory, including attention, encoding, maintenance and manipulation. We sought to clarify the contribution of functional deficits in these subprocesses in MDD by varying cognitive load during a working memory task.

Methods: 41 depressed participants and 41 age and gender-matched healthy controls performed the $n$-back working memory task at three levels of difficulty (0-, 1-, and 2-back) in a pregistered study. We assessed response times, accuracy, and event-related electroencephalography (EEG), including P2 and P3 amplitudes, and frontal theta power $(4-8 \mathrm{~Hz})$.

Results: MDD participants had prolonged response times and more positive frontal P3 amplitudes (i.e., Fz) relative to controls, mainly in the most difficult 2-back condition. Working memory accuracy, P2 amplitudes and frontal theta event-related synchronisation did not differ between groups at any level of task difficulty.

Conclusions: Depression is associated with generalized psychomotor slowing of working memory processes, and may involve compensatory hyperactivity in frontal and parietal regions.

Significance: These findings provide insights into MDD working memory deficits, indicating that depressed individuals dedicate greater levels of cortical processing and cognitive resources to achieve comparable working memory performance to controls.
\end{abstract}

\section{Introduction}

Major depressive disorder (MDD) has been linked to cognitive impairments across multiple domains, including attention, updating, and working memory (Bora et al., 2013; Harvey et al., 2004; Porter et al., 2003; Rose and Ebmeier, 2006; Snyder, 2013). Working memory is essential for maintaining and manipulating multimodal goal-relevant information for complex behaviours. Multiple cognitive subprocesses are involved in working memory (Owen et al., 2005), including sustained attention to relevant stimuli, encoding stimuli to memory, and central executive functions of maintenance and manipulation (i.e. updating) (Lepsien et al., 2011; Veltman et al., 2003). The contribution of these functions to working memory impairment in depression remains unclear. Godard et al. (2012) observed greater deficits to sustained and divided attention as well as information processing speed in depressed individuals, whereas executive functioning, including updating in working memory, was relatively preserved. Christopher and MacDonald (2005) found a generalised disruption in working memory performance, suggesting a reduced ability to re-allocate attentional resources to the current task, in agreement with studies showing impaired vigilance and sustained attention (Nilsson et al., 2016; Porter et al., 2003). Challenging these findings, other studies have reported moderate impairments to both attention and executive functioning (Cotrena et al., 2016; Rock et al., 2014), or deficits in maintenance and set-shifting ability with no significant impairments to attention and motor performance (Grant et al., 2001).

The relative contribution of attentional and central executive function deficits can be investigated using the $n$-back task, which assesses

\footnotetext{
* Corresponding author at: Black Dog Institute, Hospital Road, Randwick NSW 2031, Sydney, Australia.

E-mail address: stevan.nikolin@unsw.edu.au (S. Nikolin).
} 
working memory performance over increasing cognitive loads by varying the load factor $n$. At lower levels of cognitive load, this task predominantly tests attention, whereas greater cognitive loads place increased reliance on higher-order central executive functions such as maintenance and updating. An additional benefit of the $n$-back task is the ability to assess working memory processing speed using response times for correct responses (Nikolin et al., 2015), and to supplement behavioural outcomes with concurrent neurophysiological measures of brain activity obtained using electroencephalography (EEG). Despite broad use of the $n$-back task to compare behavioural outcomes between depressed and healthy individuals, there is a scarcity of studies that have performed similar comparisons using EEG measures to investigate the underlying neurobiology. The present study addresses this gap in the literature, using EEG to uncover the dysfunctional processes that underlie observed $n$-back working memory task impairments in depression.

Event-related potentials (ERPs) and time-frequency measures acquired using EEG during the $n$-back task can further elucidate the integrity of specific cognitive subprocesses involved in working memory. The frontal P2 ERP component has been linked to background sustained attention and context updating (Kemp et al., 2006; Luu et al., 2014; Vilà-Balló et al., 2018; Yuan et al., 2016). The P3 component is thought to be generated by the anterior cingulate cortex and the dorsolateral prefrontal cortex (DLPFC) (Bénar et al., 2007; Mulert et al., 2004), key structures for working memory (Owen et al., 2005). P3 amplitude has been shown to decrease as working memory cognitive demands increase in healthy individuals (Dong et al., 2015; Gevins and Cutillo, 1993; Han et al., 2013; McEvoy et al., 1998; Watter et al., 2001), and may reflect neural inhibition of task-irrelevant cortical activity (Polich, 2007). Both P2 and P3 amplitudes correlate positively with working memory performance in healthy participants (Dong et al., 2015; Gevins and Smith, 2000; Nikolin et al., 2018). Comparisons of depressed participants to healthy controls using an auditory oddball paradigm, which is similar to the 0-back task, have shown prolonged P3 latencies (Vandoolaeghe et al., 1998; Zhou et al., 2019) and reduced P3 amplitudes (Bruder et al., 2009; Zhou et al., 2019). Similar comparisons performed during a Sternberg short-term memory task revealed attenuated late postitive potential ERPs in depressed participants, which was exacerbated under more difficult task conditions (Pelosi et al., 2000).

Frontal midline theta $(4-8 \mathrm{~Hz})$ oscillations, originating from the anterior cingulate cortex, have also been shown to increase with working memory load (Brookes et al., 2011; Gevins et al., 1997; Jensen and Tesche, 2002; Krause et al., 2000; Lei and Roetting, 2011), although this effect is not consistently observed (Dong et al., 2015; Scharinger et al., 2017). Frontal theta is thought to reflect continuous processes such as maintenance and manipulation of memory items (Pesonen et al., 2007; Tesche and Karhu, 2000), and may be a marker of information coding (Kahana et al., 2001). Therefore, frontal theta is a sensitive measure to detect functional abnormalities to working memory processes during the $n$-back task, which requires continuous and ongoing maintenance of stimuli in memory (Schmiedt et al., 2005).

To clarify the pattern of cognitive deficits that contribute to reduced working memory performance in MDD, we investigated behavioural and EEG measures during the $n$-back task in a preregistered study (Nikolin et al., 2020). We varied the load factor $n$ from 0 to 2 to distinguish between deficits of attention and executive functioning. Based on findings from prior meta-analyses showing moderate working memory impairments in depression (Bora et al., 2013; Snyder, 2013), we hypothesised that $n$-back task performance, measured using response time and accuracy, would be worse in MDD participants compared to healthy age- and gender-matched controls. Further, we expected a greater discrepancy in performance as cognitive load on the $n$-back task increases, indicative of impairments to central executive functioning. These hypothesis were based on behavioural results, as we were unable to identify any literature of EEG comparisons of the $n$-back task between MDD and healthy participants. As P2 and P3 amplitudes, and frontal theta, are positively correlated with working memory performance (Brzezicka et al., 2019; Dong et al., 2015; Gevins et al., 2000; Nikolin et al., 2018), we hypothesised that these measures would be reduced in MDD patients relative to controls.

\section{Methods}

\subsection{Participants}

A meta-analysis of working memory impairment in MDD estimated an effect size of Cohen's $d=0.63$ using the $n$-back task (Snyder, 2013). A power analysis suggested a sample size of $n=40.5$ participants per group would be required to detect this effect (using $\alpha=0.05$, and power $1-\beta=0.8$ ). Hence, we recruited 41 MDD participants and 41 age- and gender-matched healthy controls for a total of 82 participants. This cohort has previously been investigated in a study of emotional reactivity in depression (Nikolin et al., 2020). All participants gave written informed consent, and the study protocol was approved by the University of New South Wales (UNSW) Human Research Ethics Committee (HC16617).

Depressed participants were recruited from individuals who took part in one of several research trials conducted at the Black Dog Institute, Sydney - Australia, or from those that attended depression clinics at our institute as outpatients. They were assessed by an experienced study Psychiatrist and had to meet DSM- 5 criteria for a current MDD diagnosis (American Psychiatric Association, 2013), as well as score $\geq 20$ on the Montgomery-Åsberg Depression Rating Scale for depressive symptoms (Montgomery and Asberg, 1979).

Healthy controls were recruited through research volunteer registries of the University of New South Wales (UNSW) School of Psychology and the Black Dog Institute. Healthy control participants were eligible to participate if they had no current or past psychiatric disorders and were selected to be the same gender and within five years of age of the matched MDD participants since these factors have previously been shown to influence the latency, amplitude, and topography of ERP components (Kayser et al., 2000; Oliver-Rodriguez et al., 1999; Renfroe et al., 2016).

Shared inclusion criteria for both MDD and control participants included normal or corrected-to-normal vision, aged 18 years and above, no recent serious head injury in the last 12 months (e.g. loss of consciousness of more than $30 \mathrm{~min}$ ), no neurological condition (e.g. stroke, epilepsy), no history of drug or alcohol dependence in the last three months, not pregnant or possibly pregnant, and an ability to cooperate with the EEG procedure (e.g. no tremor). All participants completed the 21-item self-reported Depression, Anxiety and Stress Scale (DASS; Lovibond and Lovibond 1995). Additionally, control participants were excluded if they had a current psychiatric diagnosis.

\subsection{Procedure}

The visual $n$-back working memory task, adapted from Mull and Seyal (2001), was administered via Inquisit software (Version 5, Millisecond Software). Participants were presented a series of letters (A-J) each flashing on the screen for $500 \mathrm{~ms}$ with an interval of $1500 \mathrm{~ms}$ between letters. The task was presented for approximately three minutes, comprising 20 target stimuli and 60 distractor cues, at each level of task difficulty (0-, 1-, and 2-back). Participants pressed the spacebar on a standard keyboard whenever they saw the letter 'A' (0-back), a letter matching the one before it (1-back), or a letter matching the one two letters previously (2-back), as quickly and as accurately as possible. Participants were given the opportunity to practise the 2-back task for one minute prior to starting the experiment. This was repeated as necessary to ensure task instructions were understood. Task performance was assessed using response time (RT) for correct responses and d-prime, a measure of discriminative sensitivity (Haatveit et al., 2010). D-prime was calculated using a z-score transformation of the difference 
between the percentage of correct responses and incorrect responses (i. e. false alarms).

\subsection{Electroencephalography data acquisition and processing}

EEG data was acquired using a TMSi Refa amplifier (TMS International, Oldenzaal, Netherlands) with a 64-channel setup and a sampling rate of $1024 \mathrm{~Hz}$. Data processing and analysis was conducted using the Fieldtrip open-source toolbox (Oostenveld et al., 2011) and custom-developed MATLAB scripts (v.R2019a; MathWorks).

EEG data was preprocessed using a Butterworth infinite impulse response (IIR) digital filter to remove $50 \mathrm{~Hz}$ electrical line noise. Following this, a second-order band-pass filter with cut-offs of 0.5 and $70 \mathrm{~Hz}$ was used to remove high and low frequency noise generated from head movements and muscle activity. EEG data was then segmented into trials, beginning $0.5 \mathrm{~s}$ before stimulus onset and continuing for $1.5 \mathrm{~s}$ following stimulus presentation. Trials with large noise artefacts were initially rejected using an automated procedure and were then visually inspected to identify and remove any remaining noisy trials and/or channels. Smaller, non-cortical physiological activity (e.g. cardiac, muscle, ocular) and non-physiological activity (e.g. environmental noise, movement) was removed using an Independent Components Analysis (ICA) algorithm (Delorme et al., 2007; Hyvärinen et al., 2001; Makeig et al., 1996). ICA was performed using the default runica function implementation in Fieldtrip. Finally, the cleaned data was re-referenced to the common average reference.

\subsubsection{Event-related potentials}

The minimum number of trials needed to generate reliable ERP components varies, but is estimated to be greater than 30 (Rietdijk et al., 2014), or at least 60 (Huffmeijer et al., 2014), for P2 and P3 components. Therefore, to obtain an adequate number of trials, ERPs were constructed by averaging target letters and distractors combined (Kao et al., 2020; Zhang et al., 2017; Zhao et al., 2017). This was done separately for each level of task difficulty. ERPs were baseline-corrected to the mean amplitude from 500 to $0 \mathrm{~ms}$ prior to stimulus onset.

Neuroimaging studies suggest that depression is characterised by dysfunctional activity within frontal regions (Kaiser et al., 2015; Mayberg, 2003; Nord et al., 2020; Wang et al., 2015). As such, P2 and P3 components were assessed at frontal EEG channel Fz (Nikolin et al., 2020). The amplitude of these components was determined by computing grand average ERPs for all participants (i.e. MDD and controls) and all $n$-back task difficulty levels combined, and isolating the mean latency for P2 and P3 components within a range of 95-195 ms, and 325-425 ms, respectively (Nikolin et al., 2018). The average amplitude was then calculated in a time interval $\pm 10 \mathrm{~ms}$ of the grand average latencies for P2 and P3 components. The ERP component latencies were identified as $142 \mathrm{~ms}$ for P2 (interval for averaging: 132-152 $\mathrm{ms}$ ), and $362 \mathrm{~ms}$ for P3 (interval for averaging: 352-372 ms).

\subsubsection{Time-frequency analysis}

Time-frequency power was calculated in single-trial data and then averaged across all trials, i.e. target letters and distractors combined. Frontal theta was calculated at each level of task difficulty using a Hanning taper with a fixed $500 \mathrm{~ms}$ time window. Theta event-related synchronisation (ERS) was defined as power in the theta frequency band $(4-8 \mathrm{~Hz})$ in the time interval from 100 to $500 \mathrm{~ms}$ following stimulus onset. We used a collapsed localiser approach (Cohen, 2014; Luck and Gaspelin, 2017), blind to group condition, to select the time interval. First, we computed the grand-average time-frequency event-related synchronisation/desynchronisation for all participants (i.e. MDD and controls) and then visually selected time windows that contained the largest power changes for the theta frequency band. This method allows the time interval of interest to be defined without bias.

Theta ERS was baseline-corrected using activity from 500 to $0 \mathrm{~ms}$ prior to stimulus onset and transformed into a decibel scale $(10 * \log 10$ of the signal).

\subsection{Statistical analyses}

Mixed effects repeated measures models (MRMMs) were performed using SPSS software (IBM SPSS Statistics 25 for Windows; SPSS Inc.). MRMMs included the fixed factors of Group (MDD or controls), Difficulty (0-, 1-, and 2-back task levels), and their interaction (Group $\times$ Difficulty). 'Participant' was included as a random effect. Covariance matrices were selected by identifying the covariance structure resulting in the lowest Bayes information criterion (BIC).

Working memory has been shown to vary with age (Gajewski and Falkenstein, 2018), gender (Speck et al., 2000), and anxiety levels (Moran, 2016). Thus, the covariates of age, gender, and anxiety - estimated from the anxiety subscore of the DASS - were tested sequentially and incorporated into MRMMs if found to substantially improve fit. Model fit was estimated using the BIC under maximum likelihood conditions. Once final MRMMs were constructed, results were obtained under restricted maximum likelihood conditions.

Post-hoc pairwise comparisons were conducted to determine the direction of the effect. Cohen's $d$ effect sizes and 95\% confidence intervals are reported as specified in our preregistration document (Nikolin et al., 2020). We tested whether the data and model residuals violated normality conditions using visual inspection and diagnostic tests of normality (i.e. Kolmogorov-Smirnov and Shapiro-Wilk tests).

Exploratory non-parametric cluster-based permutation tests were performed on ERP and time-frequency data at each level of task difficulty. This method controls for the family-wise error rate while performing statistical comparisons across a large spatiotemporal parameter space (Maris and Oostenveld, 2007; Pernet et al., 2015). Trials were randomly permuted in 3000 iterations using the Monte Carlo method. Permutation testing was performed using data from all EEG channels within the time interval $0-1000 \mathrm{~ms}$ from stimulus onset. The resultant distributions were statistically compared between MDD and control participants using non-parametric independent samples $t$-tests and a two-tailed significance threshold of $\alpha<0.05$. Statistically significant clusters comprised of at least two neighbouring channels.

Source localisation, performed using the Brainstorm toolbox (Tadel et al., 2011), determined the location of cortical sources that differed between MDD and healthy participants during the 1-back and 2-back tasks. We firstly generated a grand-average ERP of the difference between MDD and control participants across all channels. The noise covariance was then calculated based on the time interval -500 to $-1 \mathrm{~ms}$ preceding $n$-back task stimulus onset. A head model consisting of 15,002 dipoles was constructed using Open MEEG software (Gramfort et al., 2010; Kybic et al., 2005) and the default anatomy template provided by Brainstorm of the International Consortium for Brain Mapping (ICBM-152). Electrode positions were defined using the standard BrainProducts EasyCap M1 template. Inverse solutions were computed using minimum norm imaging to calculate current density maps with unconstrained source orientations to minimise assumptions.

All scripts used for Inquisit delivery of the $n$-back tasks, statistical analyses, and EEG processing using MATLAB are available at the following link: https://github.com/snikolin/MDDvsCTRL_NBACK.

\section{Results}

A total of 41 MDD participants (age range 21-76) and 41 age- and gender-matched healthy controls (age-range 21-77) were included in the study. Demographic characteristics of both groups are shown in Table 1. One MDD participant's responses were not logged during the 1back task due to a technological malfunction. The participant's RT and d-prime scores for the 1-back task were therefore excluded from statistical analyses. Responses for the 0 - and 2-back tasks were unaffected and so were included. 
Table 1

Demographic and clinical information for MDD and control participants. Means and standard deviations (SD) are shown for continuous measures, and frequency counts for categorical measures.

\begin{tabular}{lll}
\hline & MDD & Controls \\
\hline Age (years) & $46.3(13.2)$ & $46.0(13.9)$ \\
Education (years) & $15.8(3.6)$ & $17.3(3.6)$ \\
Gender (females/males) & $15 / 26$ & $15 / 26$ \\
TRD (yes/no) & $32 / 9$ & - \\
Concurrent antidepressants (yes/no) & $31 / 9$ & - \\
SSRI & 6 & - \\
SNRI & 7 & - \\
TCA & 8 & - \\
MAOI & 4 & - \\
Other & 6 & - \\
MADRS & $29.6(5.0)$ & - \\
DASS Depression & $33.7(7.1)$ & $4.2(5.2)$ \\
DASS Anxiety & $11.0(9.7)$ & $3.3(4.5)$ \\
DASS Stress & $21.3(9.5)$ & $6.8(5.5)$ \\
DASS Total & $66.5(19.7)$ & $14.2(12.9)$ \\
\hline
\end{tabular}

MDD: Major Depressive Disorder; TRD: Treatment-Resistant Depression Defined as failure to respond to at least two adequate courses of antidepressant medication; SSRI: Selective serotonin reuptake inhibitor; SNRI: Serotoninnorepinephrine reuptake inhibitor; TCA: Tricyclic antidepressant; MAOI: Monoamine oxidase inhibitor; MADRS: Montgomery-Asperg Depression Rating Scale (Montgomery et al., 1979); DASS: 21-item Depression, Anxiety and Stress Scale (Lovibond et al., 1995). DASS scores were not available for two MDD participants.

\subsection{Behavioural results}

Clear differences in performance were observed between task loads (Fig. 1). Most participants made little or no errors during the 0-back task, resulting in observable ceiling effects for d-prime scores. D-prime decreased with task load, which was confirmed by the MRMM results showing a significant main effect of Difficulty $\left(\mathrm{F}_{(2,80.4)}=33.03 ; p<\right.$ $0.001)$. There was no main effect of Group $\left(\mathrm{F}_{(1,82.7)}=2.87 ; p=0.09\right)$, and no Group $\times$ Difficulty interaction $\left(\mathrm{F}_{(2,80.4)}=1.79 ; p=0.17\right)$. Effect sizes showed differences in the expected direction with depressed
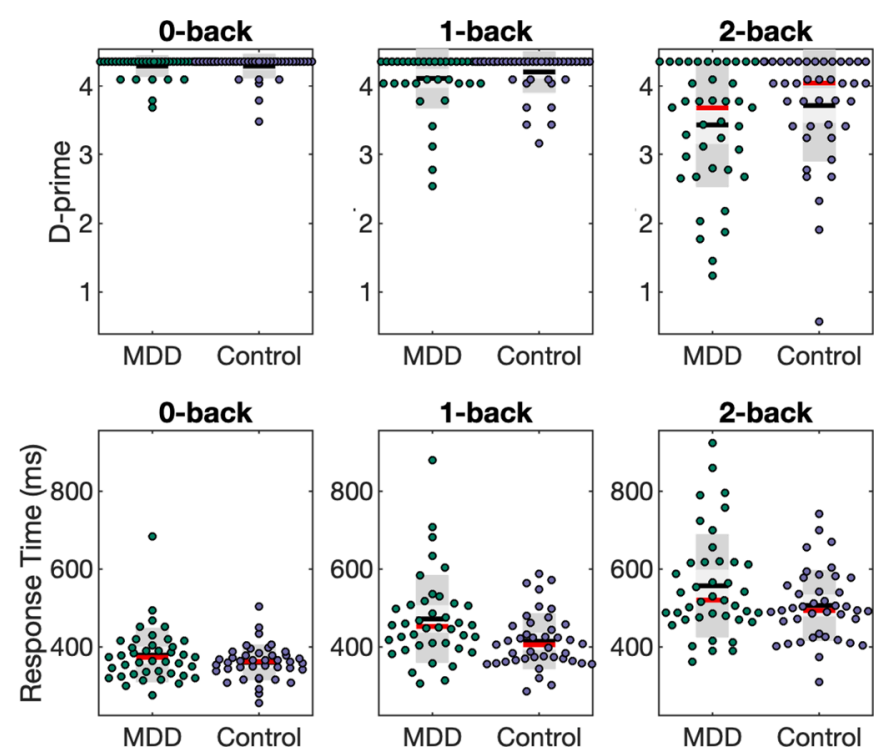

Fig. 1. $N$-back task scatterplots of behavioural outcomes. Black lines show the mean, red lines show the median, light grey shaded boxes indicate the $95 \%$ confidence interval, and dark grey regions indicate the standard deviation. Several MDD and control participants attained the maximum d-prime score (4.35), indicative of a ceiling effect. MDD: Major Depressive Disorder. (For interpretation of the references to color in this figure legend, the reader is referred to the web version of this article.) individuals demonstrating greater reductions in accuracy relative to controls with increased load (0-back task Cohen's $d=0.00$; 1-back task Cohen's $d=0.25$; and 2-back task Cohen's $d=0.33$; Table S1). Covariates of age, gender, and anxiety-level did not improve model fit, and were not incorporated into the MRMMs.

Response times increased with increasing task load, as reflected by a significant main effect of Difficulty $\left(\mathrm{F}_{(2,97.4)}=101.09 ; p<0.001\right)$. The main effect of Group was significant $\left(\mathrm{F}_{(1,83.1)}=6.74 ; p=0.01\right)$, indicating prolonged response times for correct responses in MDD participants compared to controls. The Group $\times$ Difficulty interaction effect was not significant $\left(\mathrm{F}_{(2,97.4)}=2.68 ; p=0.07\right)$. Differences between groups were in the hypothesised direction, i.e. slower response times in MDD with increased load (0-back task Cohen's $d=0.32$; 1-back task Cohen's $d=0.61$; and 2-back task Cohen's $d=0.45$; Table S1).

The data and model residuals showed signs of violations to the assumption of normality. Hence, we also performed multiple nonparametric Mann-Whitney $U$ tests to compare MDD and control participants across all $n$-back levels. These had similar findings to MRMM results, despite violations of normality (see Table S2). Briefly, no significant differences were observed in d-prime between MDD and control groups for all $n$-back task loads. A statistically significant difference for response times was found only for the 1-back condition when controlling the false discovery rate.

\subsection{Electroencephalography results}

The number of components rejected during ICA was similar between $\operatorname{MDD}(9.2 ; \mathrm{SD}=3.5 ; 2-17)$ and control participants $(7.9 ; \mathrm{SD}=3.7 ; 1-17)$. With the exception of one individual with noisy EEG data from the MDD cohort, in which only 20,18 , and 50 trials could be retained for 0-, 1-, and 2-back trials, respectively, the remaining participants had a minimum of 50 out of 80 trials (63\%) and a minimum of 61 out of 64 electrode channels available for ERP calculations for each $n$-back task load condition (Table S3). To confirm that the MDD participant with a low number of trials did not influence our findings we performed a sensitivity analysis by excluding this individual and repeated our statistical analyses. This exclusion did not substantively change our statistical findings (Table S4).

\subsubsection{Event-related potentials}

ERPs obtained from frontal midline channel Fz revealed a typical response pattern for the $n$-back task, including several discernible components (N2, P2, and P3) followed by a return to baseline activity (Supp Fig. S1).

The MRMM revealed a significant main effect of Difficulty for P2 amplitude $\left(\mathrm{F}_{(2,159.0)}=5.39 ; p=0.005\right)$, indicating greater amplitudes with increased $n$-back task load. However, the main effect of Group $\left(\mathrm{F}_{(1}\right.$, $81.7)=0.27 ; p=0.61)$ and the Group $\times$ Difficulty interaction $\left(\mathrm{F}_{(2,159.0)}\right.$ $=0.77 ; p=0.46$ ) were not significant. Follow-up Mann-Whitney $U$ tests were performed to account for observed violations to assumptions of normality and confirmed the absence of a main or interaction effect of Group (see Table S2).

Analysis of P3 amplitudes revealed that the main effect of Difficulty $\left(\mathrm{F}_{(2,136.2)}=1.88 ; p=0.16\right)$ and the Group $\times$ Difficulty interaction effect $\left(\mathrm{F}_{(2,136.2)}=0.15 ; p=0.86\right)$ were not significant. The main effect of Group $\left(\mathrm{F}_{(1,80.9)}=8.92 ; p=0.004\right)$ was significant. Contrary to our preregistered hypothesis, we observed increased P3 amplitudes in MDD participants compared to controls for the 0-back (Cohen's $d=0.55$ ), 1 back (Cohen's $d=0.56$ ), and 2-back tasks (Cohen's $d=0.68$; Table S1). Non-parametric Mann-Whitney $U$ tests revealed a significant difference in P3 amplitudes between groups for the 2-back task only ( $p=0.004)$ when controlling the false discovery rate (Table S2). Although an effect of Difficulty was not present for P3 amplitudes at our region of interest (Fz), re-analysis of amplitudes obtained from parietal channel $\mathrm{Pz}$ shows the expected amplitude reductions with increased Difficulty $\left(\left(\mathrm{F}_{(2,139.3)}\right.\right.$ = 19.7; $\mathrm{p}<0.001$; see Supplementary Materials). 
Exploratory cluster-based permutation tests were used to compare MDD and control participants for ERPs at each level of the $n$-back task. Significant frontoparietal clusters were identified for ERPs during the 1and 2-back tasks, but not the 0-back task (Fig. 2). The time interval for the significant 1-back cluster was $267-454 \mathrm{~ms}$, and $164-492 \mathrm{~ms}$ for the significant 2-back cluster.

Source localisation of grand-average difference ERPs showed areas of heightened activity in depressed individuals corresponding to visual language centres, including bilateral occipitotemporal regions, and prefrontal regions associated with executive functioning, including the dorsomedial prefrontal cortex and frontal pole (Fig. 3).

\subsubsection{Time-frequency response}

Time-frequency power showed several features consistent with cortical activity obtained during an $n$-back task: attenuation of alpha $(8-12 \mathrm{~Hz})$ activity, early beta $(12-30 \mathrm{~Hz})$ event-related desynchronization associated with motor cortical activation in preparation for a response, post-movement beta-rebounding beginning at $\sim 600 \mathrm{~ms}$ (Pesonen et al., 2007), and a prominent post-stimulus increase in frontal theta power within the time interval of interest (Fig. 4).

MRMM results for frontal theta event-related synchronisation revealed a significant main effect of Difficulty $\left(\mathrm{F}_{(2,160.0)}=4.89 ; p=\right.$ 0.01 ). Pairwise comparisons identified a significant increase in theta from 0 - to 1-back tasks (mean difference $=0.23 ; 95 \% \mathrm{CI}=0.05-0.41 ; p$ $=0.014$; Cohen's $\mathrm{d}=0.27$ ), and a significant decrease in theta from 1 - to 2-back tasks (mean difference $=-0.27 ; 95 \% \mathrm{CI}=-0.45--0.09 ; p=$ 0.004 ; Cohen's $d=-0.32$ ). There was no significant difference in theta values between 0 - and 2-back tasks (mean difference $=-0.04 ; 95 \% \mathrm{CI}=$ $-0.22-0.14 ; p=0.683$; Cohen's $d=-0.05)$. Main effects of Group $\left(\mathrm{F}_{(1}\right.$, $80.0)=0.81 ; p=0.37)$, and the Group $\times$ Difficulty interaction $\left(\mathrm{F}_{(2,160.0)}\right.$ $=1.09 ; p=0.34$ ) were not significant. Mann-Whitney $U$ tests were not significant. Cluster-based permutation tests revealed no significant clusters for time-frequency comparisons $(p>0.05)$.

The majority of MDD participants were on stable doses of standardof-care maintenance antidepressants at the time of the data collection (77.5\%; Table 1). There is some evidence to suggest that long-term antidepressant use may alter cognitive functioning (McClintock et al., 2010). To determine whether antidepressant use altered our results, we
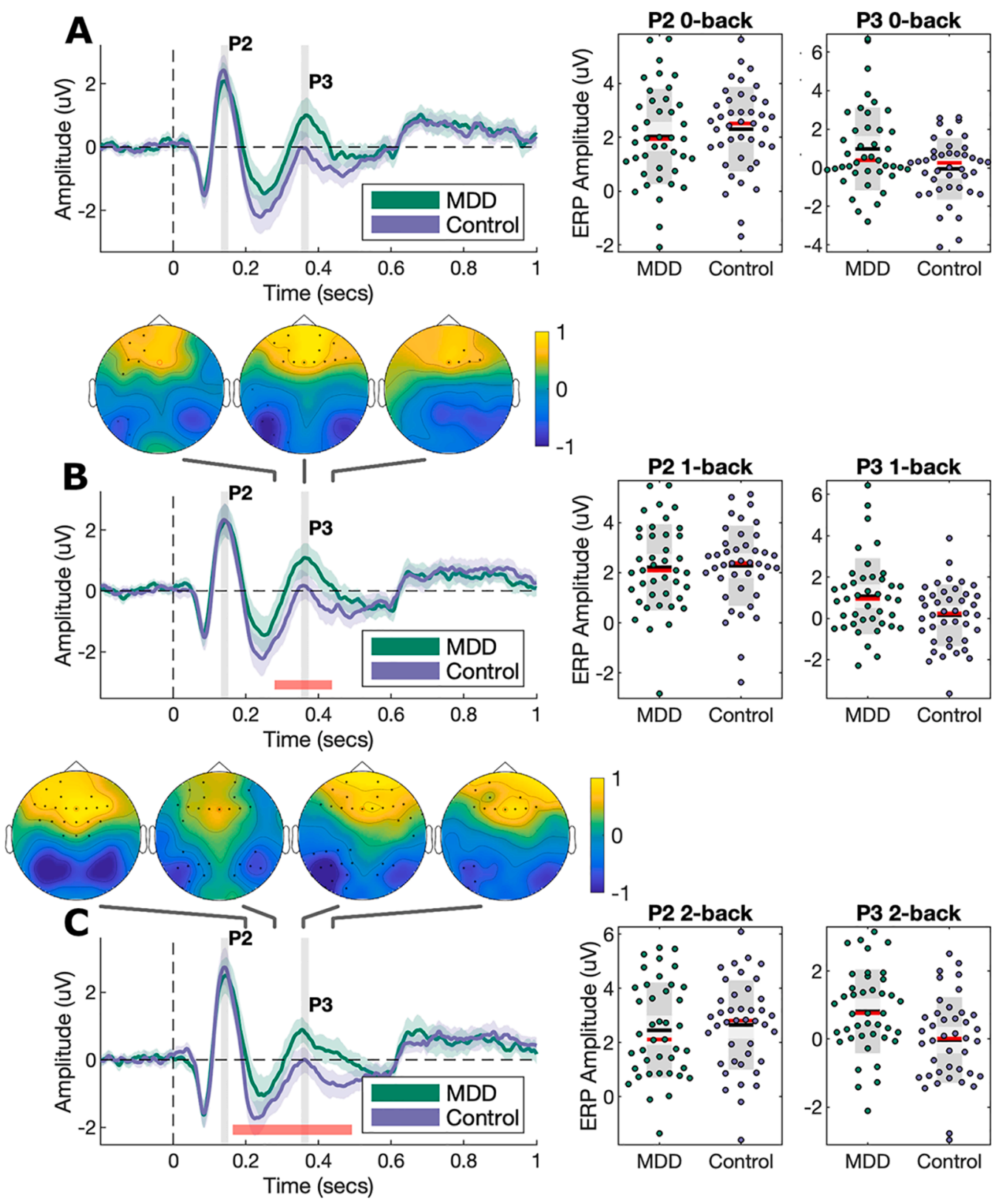

Fig. 2. Event-related potentials (ERPs) during the $n$-back task. ERPs were generated by averaging brain activity for target and distractor stimuli at a midline frontal channel $(\mathrm{Fz}$ - circled in red). ERPs are displayed with bootstrapped 95\% confidence intervals and with the time interval used to calculate P2 and P3 components shaded in light grey. Topographical plots of the difference between MDD and control participants are plotted above the time series. Cluster-based permutation tests were used to identify significant clusters electrodes forming the significant clusters are marked in black, and the significant time interval identified by analyses is indicated using the red bar. Regarding scatterplots, the black lines show the mean, red lines show the median, light grey shaded boxes indicate the $95 \%$ confidence interval, and dark grey regions indicate the standard deviation. (A) 0-back task ERP. (B) 1-back task ERP. Cluster-based permutations revealed a significant cluster occurring $279-437 \mathrm{~ms}$ post-stimulus, indicated in red. Topographical difference plots are displayed at 280, 360, and $440 \mathrm{~ms}$. (C) 2-back task ERP. Cluster-based permutations revealed a significant cluster occurring 164-492 ms post-stimulus. Topographical difference plots are displayed at 200, 280, 360, and $440 \mathrm{~ms}$. MDD: Major Depressive Disorder. (For interpretation of the references to color in this figure legend, the reader is referred to the web version of this article.) 


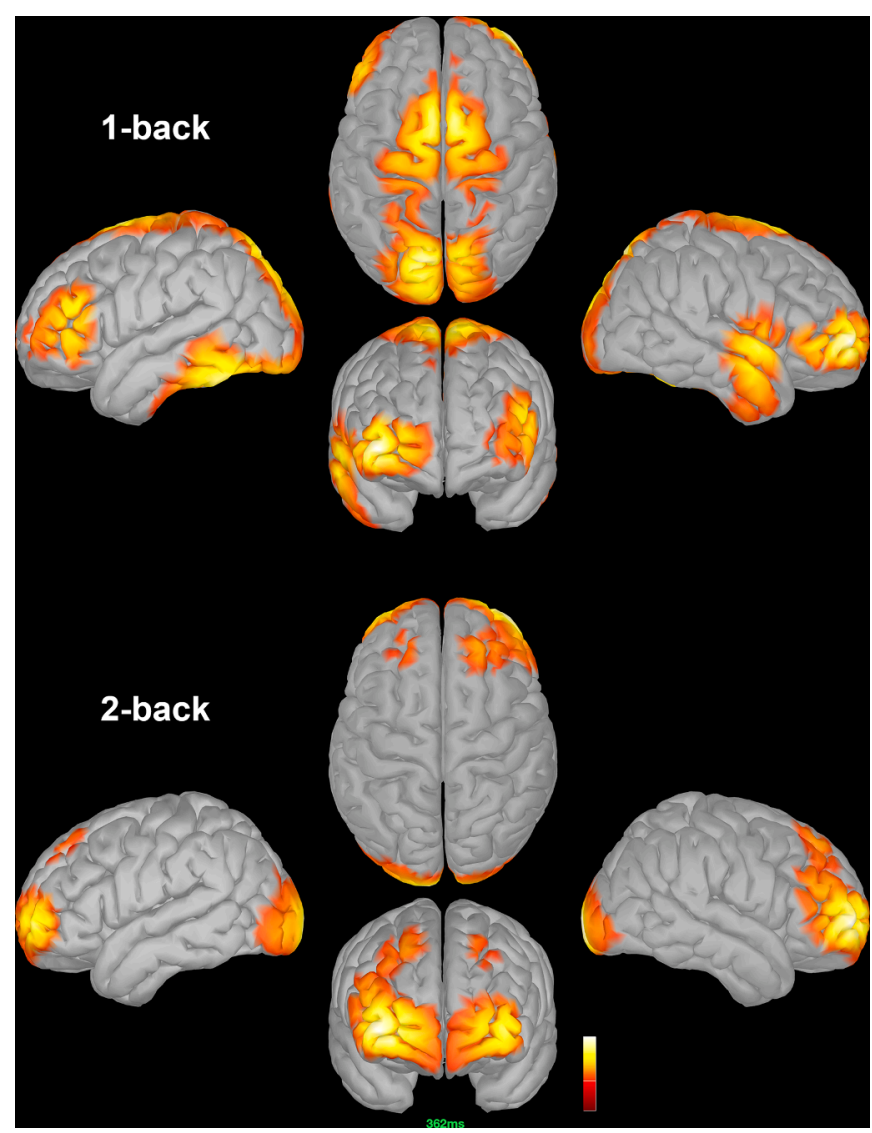

Fig. 3. Source estimation for $P 3$ amplitude differences during the $n$-back task. We performed source localisation of the ERP difference between depressed and healthy participants at $362 \mathrm{~ms}$ (i.e., the grand average latency for the P3 component) using Open MEEG and minimum norm imaging with unconstrained dipoles. Highlighted regions depict brain areas where depressed participants had greater cortical activation compared to controls. That is, the figure displays the likely source configurations of observed significant ERP differences, rather than areas of statistically significant differences in activity. The image displays cortex viewed from left, right, top, and front-facing directions.

performed additional MRMM analyses introducing 'Antidepressants' as a binary (yes/no) categorical covariate for all outcome measures. These confirmatory analyses show that results do not substantively change with the inclusion of Antidepressants with the exception of response time measures, which no longer show a significant main effect of Group ( $p=0.10$; Table S5). Follow-up analyses comparing response times between MDD individuals taking antidepressants with those not taking any antidepressants shows no difference in latency $(p=0.98)$. This suggests that the loss of statistical significance for the main effect of Group may be due to a reduction in statistical power associated with the inclusion of an additional variable in the model, rather than due to medication effects slowing response times.

\section{Discussion}

We investigated the cognitive deficits underlying reduced working memory performance in depressed individuals using the $n$-back task. Performance accuracy did not differ between MDD participants and ageand gender-matched healthy controls for all $n$-back task levels. Depressed individuals showed significantly prolonged response times, suggestive of generalised psychomotor slowing. EEG analyses revealed more positive midline frontal P3 amplitudes in MDD relative to control participants for the most difficult 2-back condition, in the direction opposite to our preregistered hypothesis. Exploratory permutation analyses confirmed these effects, revealing a significant cluster consisting
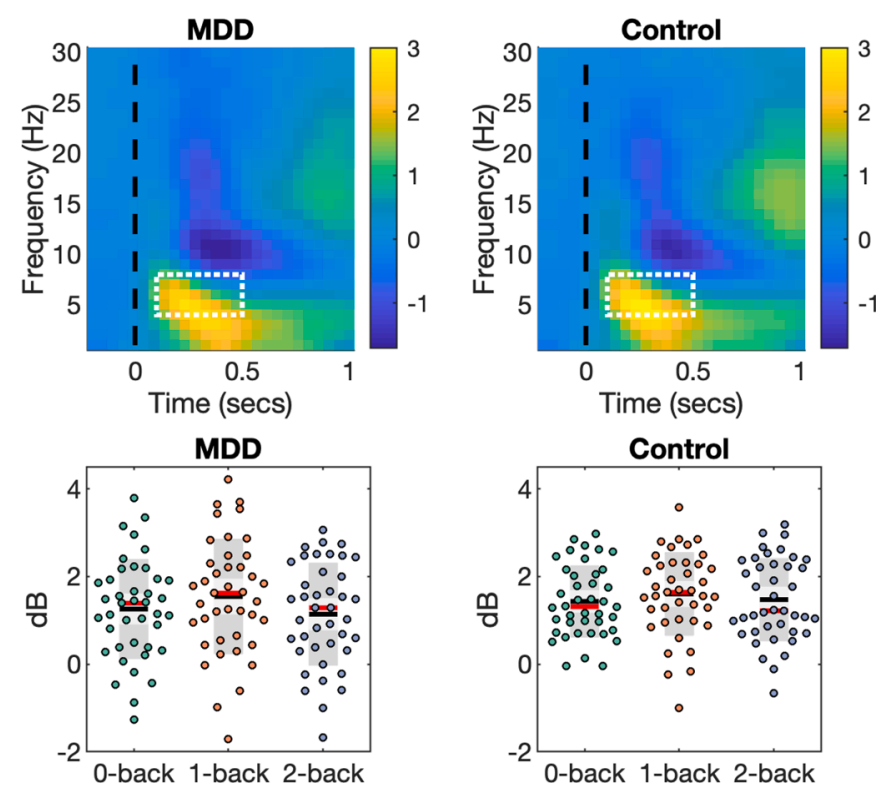

Fig. 4. Time-frequency outcomes during $n$-back task. Task-related time-frequency power was generated by averaging brain activity for target and distractor stimuli. Time-frequency plots show activity at a midline frontal channel (Fz) for the average of all $n$-back task loads. The white box indicates the region of interest for theta $(4-8 \mathrm{~Hz})$ event-related synchronisation within a time interval of 100-500 ms. Regarding scatterplots, the black lines show the mean, red lines show the median, light grey shaded boxes indicate the $95 \%$ confidence interval, and dark grey regions indicate the standard deviation. MDD: Major Depressive Disorder. (For interpretation of the references to color in this figure legend, the reader is referred to the web version of this article.)

of frontal and parietal channels at around $\sim 300 \mathrm{~ms}$ for the 1-back and 2back conditions. P2 amplitude and theta ERS did not significantly differ between groups. Collectively, these findings suggest that depressed individuals suffer from deficits to neural efficiency within the frontoparietal working memory system and a generalised reduction in processing speed.

The present study examined performance at multiple cognitive loads and found no significant difference between MDD and control participants for accuracy for all levels of the $n$-back task (0-, 1- and 2-back), suggesting that overall working memory performance is relatively well-preserved in MDD participants. However, it is important to note that a lack of significant differences does not demonstrate that differences are absent. Indeed, the small effect sizes for reduced mean d-prime scores on 1- and 2-back tasks $(d=0.25$ and $d=0.33$, respectively; Table S1) could indicate that depressed participants had impaired accuracy, but that the effect size was too small to detect with the current sample. These smaller effect sizes may have occurred due to insufficiently challenging task loads. For example, Harvey et al. (2004) reported significantly reduced accuracy at higher difficulty levels (i.e. the 1-, 2- and 3-back), but no difference on the attentional 0-back in a sample of 22 MDD participants. Additionally, ceiling effects were observed for 0- and 1-back tasks in both participant cohorts, which may have impaired attempts to discern differences in accuracy. More challenging task loads (e.g. 3-back task) may therefore be warranted. However, these can reduce accuracy rates to a level that would compromise the ability to generate representative EEG outcomes of working memory processes engaged during the $n$-back task. Further, a recent meta-analysis has found that 1-and 2-back cognitive loads are the most discriminating for accuracy performance differences between healthy and depression participants (Nikolin et al., 2021). Interestingly, Rose et al. (2006) also compared $n$-back performance from 20 non-psychotic MDD participants with controls and found significantly reduced accuracy at lower difficulty levels (i.e. the 0-, 1- and 2-back) but 
no difference on the 3-back task, suggesting that easier task loads are not entirely compromised by ceiling effects.

Analysis of response times revealed that MDD participants were significantly slower than control participants, and that this effect was relatively consistent across cognitive loads (i.e. the interaction effect was not significant). Prolonged responses times are in agreement with previous $n$-back studies (Rose et al., 2006), and meta-analyses (Ahern and Semkovska, 2017; Lee et al., 2012; White et al., 1997), suggesting a moderate degree of psychomotor retardation in participants with MDD and supporting its inclusion as one of the core features of depressive symptomatology (Bennabi et al., 2013). Previous research has found that MDD deficits in psychomotor speed may be associated with reduced white matter integrity in the motor system (Walther et al., 2012), decreased motivational drive (Treadway et al., 2012), and/or hypoactivity in left prefrontal regions at rest (Baeken et al., 2010; Cantisani et al., 2015). A potential confound to findings of prolonged response times is that depressed participants were allowed to be on stable ongoing antidepressant medications, similar to other studies using this cohort (Damborská et al., 2019; Murphy et al., 2019; Noda et al., 2018). It is possible that ongoing medications may have influenced response latencies, although statistical comparisons found no differences between medicated and unmedicated depressed participants. Though reassuring, this cannot exclude the possibility that antidepressants played a role in the current prolonged response time findings and, if so, in which direction. For example, whilst some reports suggest that antidepressants may prolong response times in depressed participants (Gorenstein et al., 2006; Van Laar et al., 2002), this effect is not consistently observed (Buyukdura et al., 2011), with a recent meta-analysis concluding that medications may instead have a positive effect on psychomotor speed (Rosenblat et al., 2016). Further, the effect may differ depending on the antidepressant medication involved and the dosage. The impact of medications on depression studies is a well-known confound, one that is difficult to remove. The current study adopted a real-world, pragmatic design, as requiring participants to wean off medications would likely have worsened their clinical condition and may have placed them at risk, including risk of suicide. The withdrawal of medication may itself alter neurochemistry, also confounding neurophysiological results. Recruitment of medication naïve or untreated patients was not feasible in this study setting.

Neither P2 amplitude, nor theta ERS, differed between MDD and control participants for all levels of the $n$-back task. P2 is thought to reflect background sustained attention (Kemp et al., 2006; Luu et al., 2014; Vilà-Balló et al., 2018; Yuan et al., 2016), whereas theta ERS has been associated with coordination of ongoing brain activity (Sauseng et al., 2010), including organisation of sequential items in working memory (Hsieh et al., 2011; Roberts et al., 2013). A recent study noted reduced task-related theta in MDD participants during time-intervals typically associated with encoding and maintenance (Murphy et al., 2019), however, this was not observed in the present study. This may be due to their use of the Sternberg verbal working memory task, which has temporally distinct phases of encoding, maintenance, and information retrieval, in contrast to the $n$-back task, which requires participants to perform these functions simultaneously and continuously. Taken together, we did not find evidence to suggest that the cognitive subprocesses indexed by neurophysiological measures P2 and theta ERS, sustained attention and maintenance, respectively, were substantively different between MDD and control groups.

We observed a significant increase in frontal P3 amplitude for MDD participants compared to controls, contrary to our preregistered hypothesis of a decrease in amplitude. This discrepancy may reflect the lack of empirical research available at the time of preregistration to formulate a more evidence-based prediction for P3 amplitudes. Although a large body of literature supports P3 amplitude reductions in depression during the auditory oddball task (Bruder et al., 2009; Campanella et al., 2012; Tenke et al., 2010; Zhao et al., 2010; Zhou et al., 2019), there is a scarcity of EEG evidence for the more complex $n$-back working memory task. The P3 component sourced during oddball and $n$-back tasks is likely to reflect differing underlying electrophysiological processes. In particular, P3 obtained during the $n$-back task is associated with higher-order central executive functions, including maintenance, updating, and cognitive control. During working memory tasks, the P3 ERP component is thought to reflect cognitive control, including goal-directed action selection (Barcelo et al., 2006; Kok, 2001; Krompinger and Simons, 2011; Periáñez and Barceló, 2009; Picton, 1992) and attentional control to facilitate matching of new stimuli with existing contents in working memory (Polich, 2007; Polich and Kok, 1995). P3 amplitude has been observed to increase in conjunction with tasks requiring greater cognitive control (Lu et al., 2017). Similarly, attenuated P3 amplitude at higher cognitive loads has been attributed to a reduction in frontal-dependent attentional control (García-Larrea and Cézanne-Bert, 1998), signifying the reorientation of neural generators of the P3 component to other task-relevant functions (McEvoy et al., 1998; Singhal and Fowler, 2004; Watter et al., 2001).

We postulate that larger P3 amplitudes may therefore reflect compensatory activity in frontoparietal regions during working memory processing in depression, indicating excessive resource allocation to cognitive control rather than to other executive functions required for $n$ back task performance. Such compensatory activity in frontal regions has previously been observed using fMRI studies of depression during the $n$-back (Harvey et al., 2005), Sternberg (Walter et al., 2007), and Stroop (Wagner et al., 2006) tasks. A meta-analysis of fMRI studies similarly reported that the DLPFC was hyperactive in depressed individuals during working memory processing compared to controls (Wang et al., 2015). EEG research has found that individuals with more depressive symptoms have a larger P3 amplitude during the Stroop task, attributed to an over-commitment of cognitive resources (Krompinger et al., 2011). Likewise, a recent study by Zhang et al. (2018) found larger frontal P2 amplitudes in depressed compared to control participants during an $n$-back task consisting of emotionally salient word stimuli, attributing the findings to excessive cognitive resources allocated during working memory updating. Our P3 findings are therefore consistent with evidence suggesting that the pathophysiology of MDD involves a disruption to the functioning of P3 source generators arising from the prefrontal and parietal cortices (Kaiser et al., 2015; Mayberg, 2003; Nord et al., 2020; Wang et al., 2015), albeit in an unexpected direction. Source reconstruction showed that bilateral occipitotemporal brain areas, thought to be involved in object representations (Polich, 2007), as well as the dorsomedial and orbitofrontal prefrontal cortices, key nodes within the default mode network that are typically suppressed during working memory activity (Bartova et al., 2015; Coutinho et al., 2016), had heightened activity in depression. Speculatively, our results may therefore be explained by the cortical inefficiency hypothesis, which suggests that depression is associated with dysfunctional activation of prefrontal neural circuits. Further research is required to confirm whether this interpretation accurately describes observed P3 amplitude increases in MDD during the $n$-back task.

As a limitation of the current study design, we only compared performance on the 0-, 1-, and 2-back tasks, whereas previous studies (at least in healthy individuals) have tested participants at levels as high as the 4-back task (for example, see Yang and Huang 2018). It is therefore unknown whether differences between MDD and control participants would become more prominent at higher cognitive loads. However, increasing working memory load also risks affecting the reliability of performance measures as participants increasingly lose the ability and motivation to complete the task successfully, as corroborated by Owen et al. (2005). An adaptive $n$-back paradigm, in which task difficulty adjusts in response to participant performance, might be a better means of avoiding both floor and ceiling effects (Zhang et al., 2019). A further limitation relates to $n$-back task modality, as differences in modality may partly explain disagreements between our non-significant behavioural findings and the significant findings reported in previous studies. For example, Harvey et al. (2004) used a letter-based $n$-back task similar to 
the present study, but displayed both upper and lower case letters, which may have increased cognitive resources required to complete the task. Rose et al. (2006) in contrast used a spatial, recall-based version of the $n$-back task in which participants were required to track the position of a coloured dot. These relatively subtle task variations may have important implications for the cognitive load experienced by the participants, even though the difficulty level ' $n$ ' is nominally equivalent. More challenging task variants, such as incorporating upper- and lower-case letter stimuli, may better highlight the discrepancy in performance between MDD and healthy individuals. Regarding neurophysiological outcomes, a limited number of trials were available to generate ERPs and so target and non-target stimuli were combined for averaging. The reason for this decision was to reduce the total duration of the experiment session and minimise participant burden, as this study forms part of a larger battery of cognitive tests. In the current study, we also varied cognitive load (0-, 1-, or 2-back) whereas future studies could increase the number of stimuli within the same duration by only considering the 2-back, which was the cognitive load that most clearly showed a difference between MDD and controls. This would allow an assessment of ERPs generated only from correct target responses on the $n$-back task. Lastly, as discussed above, the presence of concurrent medications was a possible confounding factor.

\section{Conclusions}

In conclusion, we found significantly prolonged response times and increased P3 component amplitudes for the MDD participants, but did not find group differences for working memory accuracy, P2 amplitudes and theta ERS. The increase in P3 amplitude was contrary to our preregistered hypothesis and could be indicative of compensatory frontoparietal activity in MDD participants compared to healthy age- and gender-matched controls. Together, these results suggest that neural pathways necessary for attentional, maintenance, updating cognitive processes are relatively preserved in depressed individuals. Instead, MDD may reduce neural processing efficiency within the frontoparietal cognitive control network needed for working memory functioning, resulting in impairments to processing speed and increased response times.

\section{CRediT authorship contribution statement}

Stevan Nikolin: Data curation, Formal analysis, Writing - original draft. Yi Yin Tan: Data curation, Writing - review \& editing. Donel Martin: Visualization, Writing - review \& editing. Adriano Moffa: Data curation, Writing - review \& editing. Colleen K. Loo: Visualization, Writing - review \& editing. Tjeerd W. Boonstra: Visualization, Writing - review \& editing.

\section{Declaration of Competing Interest} declare.

The authors have no actual or potential conflicts of interest to

\section{Acknowledgements}

We would like to thank William Flannery, Liyi Tan, and Nicholas Chand for their contributions to EEG acquisitions. Donel Martin and Tjeerd Boonstra were both funded by a NARSAD Young Investigator Award (Grant Numbers 24015 and 26060, respectively) from the Brain and Behavior Research Foundation.

\section{Supplementary materials}

Supplementary material associated with this article can be found, in the online version, at doi:10.1016/j.jad.2021.08.083.

\section{References}

Ahern, E., Semkovska, M., 2017. Cognitive functioning in the first-episode of major depressive disorder: a systematic review and meta-analysis. Neuropsychology 31 (1), 52.

American Psychiatric Association, 2013. Diagnostic and Statistical Manual of Mental Disorders (DSM-5®). American Psychiatric Pub.

Baeken, C., De Raedt, R., Santermans, L., Zeeuws, D., Vanderhasselt, M.A., Meers, M., Vanderbruggen, N., 2010. HF-rTMS treatment decreases psychomotor retardation in medication-resistant melancholic depression. Prog. Neuropsychopharmacol. Biol. Psychiatry 34 (4), 684-687.

Barcelo, F., Escera, C., Corral, M.J., Periáñez, J.A., 2006. Task switching and novelty processing activate a common neural network for cognitive control. J. Cogn. Neurosci. 18 (10), 1734-1748.

Bartova, L., Meyer, B.M., Diers, K., Rabl, U., Scharinger, C., Popovic, A., Pail, G., Kalcher, K., Boubela, R.N., Huemer, J., 2015. Reduced default mode network suppression during a working memory task in remitted major depression. J. Psychiatr. Res. 64, 9-18.

Bénar, C.G., Schön, D., Grimault, S., Nazarian, B., Burle, B., Roth, M., Badier, J.M., Marquis, P., Liegeois-Chauvel, C., Anton, J.L., 2007. Single-trial analysis of oddball event-related potentials in simultaneous EEG-fMRI. Hum. Brain Mapp. 28 (7), 602-613.

Bennabi, D., Vandel, P., Papaxanthis, C., Pozzo, T., Haffen, E., 2013. Psychomotor retardation in depression: a systematic review of diagnostic, pathophysiologic, and therapeutic implications. Biomed. Res. Int. 2013, 158746.

Bora, E., Harrison, B.J., Yücel, M., Pantelis, C., 2013. Cognitive impairment in euthymic major depressive disorder: a meta-analysis. Psychol. Med. 43 (10), 2017-2026.

Brookes, M.J., Wood, J.R., Stevenson, C.M., Zumer, J.M., White, T.P., Liddle, P.F., Morris, P.G., 2011. Changes in brain network activity during working memory tasks: a magnetoencephalography study. Neuroimage 55 (4), 1804-1815.

Bruder, G.E., Kroppmann, C.J., Kayser, J., Stewart, J.W., McGrath, P.J., Tenke, C.E., 2009. Reduced brain responses to novel sounds in depression: P3 findings in a novelty oddball task. Psychiatry Res. 170 (2-3), 218-223.

Brzezicka, A., Kamiński, J., Reed, C.M., Chung, J.M., Mamelak, A.N., Rutishauser, U., 2019. Working memory load-related theta power decreases in dorsolateral prefrontal cortex predict individual differences in performance. J. Cogn. Neurosci. 31 (9), 1290-1307.

Buyukdura, J.S., McClintock, S.M., Croarkin, P.E., 2011. Psychomotor retardation in depression: biological underpinnings, measurement, and treatment. Prog. Neuropsychopharmacol. Biol. Psychiatry 35 (2), 395-409.

Campanella, S., Delle-Vigne, D., Kornreich, C., Verbanck, P., 2012. Greater sensitivity of the P300 component to bimodal stimulation in an event-related potentials oddball task. Clin. Neurophysiol. 123 (5), 937-946.

Cantisani, A., Koenig, T., Horn, H., Müller, T., Strik, W., Walther, S., 2015. Psychomotor retardation is linked to frontal alpha asymmetry in major depression. J. Affect. Disord. 188, 167-172.

Christopher, G., MacDonald, J., 2005. The impact of clinical depression on working memory. Cogn. Neuropsychiatry 10 (5), 379-399.

Cohen, M., 2014. Time-Frequency Power and Baseline Normalizations Analyzing Neural Time Series Data: Theory and Practice. MIT Press, USA.

Cotrena, C., Branco, L.D., Shansis, F.M., Fonseca, R.P., 2016. Executive function impairments in depression and bipolar disorder: association with functional impairment and quality of life. J. Affect. Disord. 190, 744-753.

Coutinho, J.F., Fernandesl, S.V., Soares, J.M., Maia, L., Gonçalves, Ó.F., Sampaio, A., 2016. Default mode network dissociation in depressive and anxiety states. Brain Imaging Behav. 10 (1), 147-157.

Damborská, A., Tomescu, M.I., Honzírková, E., Barteček, R., Hořínková, J., Fedorová, S., Ondruš, Š., Michel, C.M., 2019. EEG resting-state large-scale brain network dynamics are related to depressive symptoms. Front. Psychiatry 10, 548.

Delorme, A., Sejnowski, T., Makeig, S., 2007. Enhanced detection of artifacts in EEG data using higher-order statistics and independent component analysis. Neuroimage 34 (4), 1443-1449.

Dong, S., Reder, L.M., Yao, Y., Liu, Y., Chen, F., 2015. Individual differences in working memory capacity are reflected in different ERP and EEG patterns to task difficulty. Brain Res. 1616, 146-156.

Gajewski, P.D., Falkenstein, M., 2018. ERP and behavioral effects of physical and cognitive training on working memory in aging: a randomized controlled study. Neural Plast. 2018, 3454835. https://doi.org/10.1155/2018/3454835.

García-Larrea, L., Cézanne-Bert, G., 1998. P3, positive slow wave and working memory load: a study on the functional correlates of slow wave activity. Electroencephalogr. Clin. Neurophysiol. 108 (3), 260-273.

Gevins, A., Cutillo, B., 1993. Spatiotemporal dynamics of component processes in human working memory. Electroencephalogr. Clin. Neurophysiol. 87 (3), 128-143.

Gevins, A., Smith, M.E., 2000. Neurophysiological measures of working memory and individual differences in cognitive ability and cognitive style. Cereb. Cortex 10 (9), 829-839.

Gevins, A., Smith, M.E., McEvoy, L., Yu, D., 1997. High-resolution EEG mapping of cortical activation related to working memory: effects of task difficulty, type of processing, and practice. Cereb. Cortex 7 (4), 374-385.

Godard, J., Baruch, P., Grondin, S., Lafleur, M.F., 2012. Psychosocial and neurocognitive functioning in unipolar and bipolar depression: a 12-month prospective study. Psychiatry Res. 196 (1), 145-153.

Gorenstein, C., De Carvalho, S.C., Artes, R., Moreno, R.A., Marcourakis, T., 2006. Cognitive performance in depressed patients after chronic use of antidepressants. Psychopharmacology 185 (1), 84-92 (Berl.). 
Gramfort, A., Papadopoulo, T., Olivi, E., Clerc, M., 2010. OpenMEEG: opensource software for quasistatic bioelectromagnetics. Biomed. Eng. Online 9 (1), 1-20.

Grant, M.M., Thase, M.E., Sweeney, J.A., 2001. Cognitive disturbance in outpatient depressed younger adults: evidence of modest impairment. Biol. Psychiatry 50 (1), $35-43$.

Haatveit, B.C., Sundet, K., Hugdahl, K., Ueland, T., Melle, I., Andreassen, O.A., 2010. The validity of d prime as a working memory index: results from the "Bergen n-back task. J. Clin. Exp. Neuropsychol. 32 (8), 871-880.

Han, L., Liu, Y., Zhang, D., Jin, Y., Luo, Y., 2013. Low-arousal speech noise improves performance in N-back task: an ERP study. PLoS One 8 (10). https://doi.org/ 10.1371/journal.pone.0076261 e76261-e76261.

Harvey, P., Le Bastard, G., Pochon, J., Levy, R., Allilaire, J., Dubois, B., Fossati, P., 2004. Executive functions and updating of the contents of working memory in unipolar depression. J. Psychiatr. Res. 38 (6), 567-576.

Harvey, P.O., Fossati, P., Pochon, J.B., Levy, R., LeBastard, G., Lehéricy, S., Allilaire, J.F., Dubois, B., 2005. Cognitive control and brain resources in major depression: an fMRI study using the n-back task. Neuroimage 26 (3), 860-869.

Hsieh, L.T., Ekstrom, A.D., Ranganath, C., 2011. Neural oscillations associated with item and temporal order maintenance in working memory. J. Neurosci. 31 (30), 10803-10810.

Huffmeijer, R., Bakermans-Kranenburg, M.J., Alink, L.R., Van IJzendoorn, M.H., 2014. Reliability of event-related potentials: the influence of number of trials and electrodes. Physiol. Behav. 130, 13-22.

Hyvärinen, A., Hoyer, P.O., Inki, M., 2001. Topographic independent component analysis. Neural Comput. 13 (7), 1527-1558.

Jensen, O., Tesche, C.D., 2002. Frontal theta activity in humans increases with memory load in a working memory task. Eur. J. Neurosci. 15 (8), 1395-1399.

Kahana, M.J., Seelig, D., Madsen, J.R., 2001. Theta returns. Curr. Opin. Neurobiol. 11 (6), 739-744.

Kaiser, R.H., Andrews-Hanna, J.R., Wager, T.D., Pizzagalli, D.A., 2015. Large-scale network dysfunction in major depressive disorder: a meta-analysis of resting-state functional connectivity. JAMA Psychiatry 72 (6), 603-611.

Kao, S.C., Wang, C.H., Hillman, C.H., 2020. Acute effects of aerobic exercise on response variability and neuroelectric indices during a serial n-back task. Brain Cogn. 138, 105508.

Kayser, J., Bruder, G.E., Tenke, C.E., Stewart, J.E., Quitkin, F.M., 2000. Event-related potentials (ERPs) to hemifield presentations of emotional stimuli: differences between depressed patients and healthy adults in P3 amplitude and asymmetry. Int. J. Psychophysiol. 36 (3), 211-236.

Kemp, A.H., Hopkinson, P.J., Stephan, B.C., Clark, C.R., Gordon, E., Bryant, R.A., Williams, L.M., 2006. Predicting severity of non-clinical depression: preliminary findings using an integrated approach. J. Integr. Neurosci. 5 (1), 89-110.

Kok, A., 2001. On the utility of P3 amplitude as a measure of processing capacity. Psychophysiology 38 (3), 557-577.

Krause, C.M., Sillanmäki, L., Koivisto, M., Saarela, C., Häggqvist, A., Laine, M., Hämäläinen, H., 2000. The effects of memory load on event-related EEG desynchronization and synchronization. Clin. Neurophysiol. Off. J. Int. Fed. Clin. Neurophysiol. 111 (11), 2071-2078.

Krompinger, J.W., Simons, R.F., 2011. Cognitive inefficiency in depressive undergraduates: stroop processing and ERPs. Biol. Psychol. 86 (3), 239-246.

Kybic, J., Clerc, M., Abboud, T., Faugeras, O., Keriven, R., Papadopoulo, T., 2005. A common formalism for the integral formulations of the forward EEG problem. IEEE Trans. Med. Imaging 24 (1), 12-28.

Lee, R.S., Hermens, D.F., Porter, M.A., Redoblado-Hodge, M.A., 2012. A meta-analysis of cognitive deficits in first-episode major depressive disorder. J. Affect. Disord. 140 (2), 113-124.

Lei, S., Roetting, M., 2011. Influence of task combination on EEG spectrum modulation for driver workload estimation. Hum. Factors 53 (2), 168-179.

Lepsien, J., Thornton, I., Nobre, A.C., 2011. Modulation of working-memory maintenance by directed attention. Neuropsychologia 49 (6), 1569-1577.

Lovibond, P.F., Lovibond, S.H., 1995. The structure of negative emotional states: comparison of the depression anxiety stress scales (DASS) with the beck depression and anxiety inventories. Behav. Res. Ther. 33 (3), 335-343.

Lu, M., Doñamayor, N., Muente, T.F., Bahlmann, J., 2017. Event-related potentials and neural oscillations dissociate levels of cognitive control. Behav. Brain Res. 320, 154-164.

Luck, S.J., Gaspelin, N., 2017. How to get statistically significant effects in any ERP experiment (and why you shouldn't). Psychophysiology 54 (1), 146-157.

Luu, P., Caggiano, D., Geyer, A., Lewis, J., Cohn, J., Tucker, D., 2014. Time-course of cortical networks involved in working memory. Front. Hum. Neurosci. 8 (4) https:// doi.org/10.3389/fnhum.2014.00004.

Makeig, S., Bell, A.J., Jung, T.P., Sejnowski, T.J., 1996. Independent component analysis of electroencephalographic data. Adv. Neural Inf. Process. Syst. 8, 145-151.

Maris, E., Oostenveld, R., 2007. Nonparametric statistical testing of EEG-and MEG-data. J. Neurosci. Methods 164 (1), 177-190.

Mayberg, H.S., 2003. Modulating dysfunctional limbic-cortical circuits in depression: towards development of brain-based algorithms for diagnosis and optimised treatment. Br. Med. Bull. 65 (1), 193-207.

McClintock, S.M., Husain, M.M., Greer, T.L., Cullum, C.M., 2010. Association between depression severity and neurocognitive function in major depressive disorder: a review and synthesis. Neuropsychology 24 (1), 9.

McEvoy, L.K., Smith, M.E., Gevins, A., 1998. Dynamic cortical networks of verbal and spatial working memory: effects of memory load and task practice. Cereb. Cortex 8 (7), 563-574.

Montgomery, S.A., Asberg, M., 1979. A new depression scale designed to be sensitive to change. Br. J. Psychiatry 134, 382-389.
Moran, T., 2016. Anxiety and working memory capacity: A meta-analysis and narrative review. Psychol. Bull. 142 (8), 831-864.

Mulert, C., Jäger, L., Schmitt, R., Bussfeld, P., Pogarell, O., Möller, H.J., Juckel, G., Hegerl, U., 2004. Integration of fMRI and simultaneous EEG: towards a comprehensive understanding of localization and time-course of brain activity in target detection. Neuroimage 22 (1), 83-94.

Mull, B.R., Seyal, M., 2001. Transcranial magnetic stimulation of left prefrontal cortex impairs working memory. Clin. Neurophysiol. Off. J. Int. Fed. Clin. Neurophysiol. 112 (9), 1672-1675.

Murphy, O., Hoy, K., Wong, D., Bailey, N., Fitzgerald, P.B., Segrave, R., 2019. Individuals with depression display abnormal modulation of neural oscillatory activity during working memory encoding and maintenance. Biol. Psychol. 148, 107766.

Nikolin, S., Chand, N., Martin, D., Rushby, J., Loo, C., Boonstra, T., 2020. EEG Correlates of Affective Processing in major Depressive Disorder. medRxiv.

Nikolin, S., Loo, C.K., Bai, S., Dokos, S., Martin, D.M., 2015. Focalised stimulation using high definition transcranial direct current stimulation (HD-tDCS) to investigate declarative verbal learning and memory functioning. Neuroimage 117, 11-19.

Nikolin, S., Martin, D., Loo, C.K., Boonstra, T.W., 2018. Effects of TDCS dosage on working memory in healthy participants. Brain Stimul. 11 (3), 518-527.

Nikolin, S., Martin, D., Loo, C.K., Iacoviello, B.M., Boonstra, T.W., 2020. Assessing neurophysiological changes associated with combined transcranial direct current stimulation and cognitive emotional training for treatment-resistant depression. Eur. J. Neurosci. 51 (10), 2119-2133.

Nikolin, S., Tan, Y.Y., Martin, D., Moffa, A., Loo, C.K., Boonstra, T., 2020. An investigation of behavioural and neurophysiological differences in working memory function of depressed patients and healthy controls. OSF. https://doi.org/10.17605/ OSF.IO/GJR6Q.

Nikolin, S., Tan, Y.Y., Schwaab, A., Moffa, A., Loo, C.K., Martin, D., 2021. An investigation of working memory deficits in depression using the n-back task: a systematic review and meta-analysis. J. Affect. Disord. 284, 1-8.

Nilsson, J., Thomas, A.J., Stevens, L., McAllister-Williams, R.H., Ferrier, I.N., Gallagher, P., 2016. The interrelationship between attentional and executive deficits in major depressive disorder. Acta Psychiatr. Scand. 134 (1), 73-82.

Noda, Y., Zomorrodi, R., Vila-Rodriguez, F., Downar, J., Farzan, F., Cash, R.F., Rajji, T.K., Daskalakis, Z.J., Blumberger, D.M., 2018. Impaired neuroplasticity in the prefrontal cortex in depression indexed through paired associative stimulation. Depress. Anxiety 35 (5), 448-456.

Nord, C., Halahakoon, D., Lally, N., Limbachya, T., Pilling, S., Roiser, J., 2020. The neural basis of hot and cold cognition in depressed patients, unaffected relatives, and low-risk healthy controls: an fMRI investigation. J. Affect. Disord. 274, 389-398.

Oliver-Rodriguez, J.C., Guan, Z., Johnston, V.S., 1999. Gender differences in late positive components evoked by human faces. Psychophysiology 36 (2), 176-185.

Oostenveld, R., Fries, P., Maris, E., Schoffelen, J.M., 2011. FieldTrip: open source software for advanced analysis of MEG, EEG, and invasive electrophysiological data. Comput. Intell. Neurosci. 2011, 1.

Owen, A.M., McMillan, K.M., Laird, A.R., Bullmore, E., 2005. N-back working memory paradigm: a meta-analysis of normative functional neuroimaging studies. Hum. Brain Mapp. 25 (1), 46-59.

Pelosi, L., Slade, T., Blumhardt, L., Sharma, V., 2000. Working memory dysfunction in major depression: an event-related potential study. Clin. Neurophysiol. 111 (9), 1531-1543.

Periáñez, J.A., Barceló, F., 2009. Updating sensory versus task representations during task-switching: insights from cognitive brain potentials in humans. Neuropsychologia 47 (4), 1160-1172.

Pernet, C., Latinus, M., Nichols, T., Rousselet, G., 2015. Cluster-based computational methods for mass univariate analyses of event-related brain potentials/fields: a simulation study. J. Neurosci. Methods 250, 85-93.

Pesonen, M., Hämäläinen, H., Krause, C.M., 2007. Brain oscillatory 4-30 Hz responses during a visual n-back memory task with varying memory load. Brain Res. 1138, $171-177$.

Picton, T.W., 1992. The P300 wave of the human event-related potential. J. Clin. Neurophysiol. 9 (4), 456-479.

Polich, J., 2007. Updating P300: an integrative theory of P3a and P3b. Clin. Neurophysiol. Off. J. Int. Fed. Clin. Neurophysiol. 118 (10), 2128-2148.

Polich, J., Kok, A., 1995. Cognitive and biological determinants of P300: an integrative review. Biol. Psychol. 41 (2), 103-146.

Porter, R.J., Gallagher, P., Thompson, J.M., Young, A.H., 2003. Neurocognitive impairment in drug-free patients with major depressive disorder. Br. J. Psychiatry 182 (3), 214-220.

Renfroe, J.B., Bradley, M.M., Sege, C.T., Bowers, D., 2016. Emotional modulation of the late positive potential during picture free viewing in older and young adults. PLoS One 11 (9), e0162323.

Rietdijk, W.J., Franken, I.H., Thurik, A.R., 2014. Internal consistency of event-related potentials associated with cognitive control: N2/P3 and ERN/Pe. PLoS One 9 (7), e102672.

Roberts, B.M., Hsieh, L.T., Ranganath, C., 2013. Oscillatory activity during maintenance of spatial and temporal information in working memory. Neuropsychologia 51 (2), 349-357.

Rock, P., Roiser, J., Riedel, W., Blackwell, A., 2014. Cognitive impairment in depression: a systematic review and meta-analysis. Psychol. Med. 44 (10), 2029-2040.

Rose, E., Ebmeier, K., 2006. Pattern of impaired working memory during major depression. J. Affect. Disord. 90 (2), 149-161.

Rosenblat, J.D., Kakar, R., McIntyre, R.S., 2016. The cognitive effects of antidepressants in major depressive disorder: a systematic review and meta-analysis of randomized clinical trials. Int. J. Neuropsychopharmacol. 19 (2), pyv082. 
Sauseng, P., Griesmayr, B., Freunberger, R., Klimesch, W., 2010. Control mechanisms in working memory: a possible function of EEG theta oscillations. Neurosci. Biobehav. Rev. 34 (7), 1015-1022.

Scharinger, C., Soutschek, A., Schubert, T., Gerjets, P., 2017. Comparison of the working memory load in n-back and working memory span tasks by means of EEG frequency band power and P300 amplitude. Front. Hum. Neurosci. 11 (6), 6.

Schmiedt, C., Brand, A., Hildebrandt, H., Basar-Eroglu, C., 2005. Event-related theta oscillations during working memory tasks in patients with schizophrenia and healthy controls. Cogn. Brain Res. 25 (3), 936-947.

Singhal, A., Fowler, B., 2004. The differential effects of Sternberg short-and long-term memory scanning on the late Nd and P300 in a dual-task paradigm. Cogn. Brain Res. 21 (1), 124-132.

Snyder, H.R., 2013. Major depressive disorder is associated with broad impairments on neuropsychological measures of executive function: a meta-analysis and review. Psychol. Bull. 139 (1), 81.

Speck, O., Ernst, T., Braun, J., Koch, C., Miller, E., Chang, L., 2000. Gender differences in the functional organization of the brain for working memory. Neuroreport 11 (11), 2581-2585.

Tadel, F., Baillet, S., Mosher, J.C., Pantazis, D., Leahy, R.M., 2011. Brainstorm: a userfriendly application for MEG/EEG analysis. Comput. Intell. Neurosci. 2011, 13. https://doi.org/10.1155/2011/879716.

Tenke, C.E., Kayser, J., Stewart, J.W., Bruder, G.E., 2010. Novelty P3 reductions in depression: characterization using principal components analysis (PCA) of current source density (CSD) waveforms. Psychophysiology 47 (1), 133-146.

Tesche, C., Karhu, J., 2000. Theta oscillations index human hippocampal activation during a working memory task. Proc. Natl Acad. Sci. 97 (2), 919-924.

Treadway, M.T., Bossaller, N.A., Shelton, R.C., Zald, D.H., 2012. Effort-based decisionmaking in major depressive disorder: a translational model of motivational anhedonia. J. Abnorm. Psychol. 121 (3), 553.

Van Laar, M., Volkerts, E., Verbaten, M., Trooster, S., van Megen, H., Kenemans, J., 2002. Differential effects of amitriptyline, nefazodone and paroxetine on performance and brain indices of visual selective attention and working memory. Psychopharmacology 162 (4), 351-363 (Berl.).

Vandoolaeghe, E., van Hunsel, F., Nuyten, D., Maes, M., 1998. Auditory event related potentials in major depression: prolonged P300 latency and increased P200 amplitude. J. Affect. Disord. 48 (2-3), 105-113.

Veltman, D.J., Rombouts, S.A., Dolan, R.J., 2003. Maintenance versus manipulation in verbal working memory revisited: an fMRI study. Neuroimage 18 (2), 247-256.

Vilà-Balló, A., Salmi, J., Soveri, A., Rodríguez-Fornells, A., Lehtonen, M., Laine, M., 2018. Neural signatures for active maintenance and interference during working memory updating. Biol. Psychol. 132, 233-243. https://doi.org/10.1016/j. biopsycho.2018.01.007.

Wagner, G., Sinsel, E., Sobanski, T., Köhler, S., Marinou, V., Mentzel, H.J., Sauer, H., Schlösser, R.G., 2006. Cortical inefficiency in patients with unipolar depression: an event-related FMRI study with the Stroop task. Biol. Psychiatry 59 (10), 958-965.

Walter, H., Wolf, R.C., Spitzer, M., Vasic, N., 2007. Increased left prefrontal activation in patients with unipolar depression: an event-related, parametric, performancecontrolled fMRI study. J. Affect. Disord. 101 (1-3), 175-185.

Walther, S., Hügli, S., Höfle, O., Federspiel, A., Horn, H., Bracht, T., Wiest, R., Strik, W., Müller, T.J., 2012. Frontal white matter integrity is related to psychomotor retardation in major depression. Neurobiol. Dis. 47 (1), 13-19.

Wang, X.L., Du, M.Y., Chen, T.L., Chen, Z.Q., Huang, X.Q., Luo, Y., Zhao, Y.J., Kumar, P., Gong, Q.Y., 2015. Neural correlates during working memory processing in major depressive disorder. Prog. Neuropsychopharmacol. Biol. Psychiatry 56, 101-108.

Watter, S., Geffen, G.M., Geffen, L.B., 2001. The n-back as a dual-task: P300 morphology under divided attention. Psychophysiology 38 (6), 998-1003.

White, D.A., Myerson, J., Hale, S., 1997. How cognitive is psychomotor slowing in depression? Evidence from a meta-analysis. Neuropsychol. Dev. Cogn. B Aging Neuropsychol. Cogn. 4 (3), 166-174.

Yang, C.Y., Huang, C.K., 2018. Working-memory evaluation based on EEG signals during n-back tasks. J. Integr. Neurosci. 17 (3-4), 695-707.

Yuan, Y., Leung, A.W.S., Duan, H., Zhang, L., Zhang, K., Wu, J., Qin, S., 2016. The effects of long-term stress on neural dynamics of working memory processing: an investigation using ERP. Sci. Rep. 6 https://doi.org/10.1038/srep23217, 2321723217.

Zhang, D., Xie, H., He, Z., Wei, Z., Gu, R., 2018. Impaired working memory updating for emotional stimuli in depressed patients. Front. Behav. Neurosci. 12, 65.

Zhang, Q., Yang, X., Yao, L., Zhao, X., 2017. Working memory load-dependent spatiotemporal activity of single-trial P3 response detected with an adaptive wavelet denoiser. Neuroscience 346, 64-73.

Zhang, Y.J., Wang, H.Y., Yan, C., Wang, L.L., Cheung, E.F.C., Chan, R.C.K., 2019. Working memory training can improve anhedonia in college students with subsyndromal depressive symptoms. Psych. J. https://doi.org/10.1002/pchj.271.

Zhao, L., Gong, J., Chen, C., Miao, D., 2010. Event-related potential based evidence of cognitive dysfunction in patients during the first episode of depression using a novelty oddball task. Psychiatry Res. Neuroimaging 182 (1), 58-66.

Zhao, X., Li, X., Yao, L., 2017. Localized fluctuant oscillatory activity by working memory load: a simultaneous EEG-fMRI study. Front. Behav. Neurosci. 11, 215.

Zhou, L., Wang, G., Nan, C., Wang, H., Liu, Z., Bai, H., 2019. Abnormalities in P300 components in depression: an ERP-sLORETA study. Nord. J. Psychiatry 73 (1), 1-8. 